\title{
41 \\ CHALLENGES FOR PARTICIPATORY ACTION RESEARCH IN INDUSTRY-FUNDED INFORMATION SYSTEMS PROJECTS
}

\author{
Karin Breu \\ Cranfield School of Management \\ Christopher J. Hemingway \\ Cranfield School of Management \\ Joe Peppard \\ Loughborough University
}

\begin{abstract}
The purpose of this position paper is to open a discussion about the practicability of participatory action research (PAR) within industry-funded information systems (IS) research. We reflect on a project in which the undue exercise of power by the practitioners on the research team compromised the methodological rigor of the inquiry. Theories of power are used to articulate our reflections and develop suggestions for mitigating power imbalances on PAR research teams, although we conclude that PAR cannot be followed faithfully to its principles in industry-funded engagements.
\end{abstract}

Keywords: Industry-funded research, participatory action research, power

\section{INTRODUCTION}

Knowledge is power and the ability to create knowledge is power (Reason 1993). As a knowledge-creating process, social scientific research inevitably involves power relations. Participatory action research (PAR) was conceived as a way of overcoming power imbalances in social scientific research (Freire 1970). Industry-funded PAR involves collaboration with powerful professionals typically occupying executive 
positions in large corporations. Information systems research often takes place with such stakeholders, yet existing accounts of PAR provide neither analyses of power dynamics on researcher-practitioner teams nor guidance on how to address power imbalances.

This position paper reflects upon power dynamics in a PAR team within an industry-funded research project. The paper draws on power theory to elicit sources of power and their uses by members of the PAR team. The paper, a reflection by the researchers, develops suggestions for attaining power balance within PAR teams, although we conclude that PAR cannot be followed faithfully to its principles in industry-funded engagements.

\section{PARTICIPATORY ACTION RESEARCH}

The participatory paradigm upholds the epistemological stance of social reality being cocreated by all humans, rather than deterministically predefined (Skolimowski 1994). The notion of a cocreated reality implicates participatory methodologies as the only legitimate means for producing knowledge or, in other words, defining reality (Fals-Borda and Rahman 1991). Originating from research on oppressed peoples and disadvantaged minorities in developing countries, PAR recognizes knowledge as an instrument of power, domination, and control (Freire 1970). A participatory worldview posits a research practice that insists on the full participation of researchers and practitioners in the dual roles of coresearchers and copractitioners in the inquiry process (Heron and Reason 1997). The fundamental difference between PAR and action research emerges from the level of involvement of the practitioner in the research process. Action research is a strategy for doing research on people, whereas PAR is committed to research with people by inviting practitioners to participate in the analysis of their own reality (Heron 1981). PAR is also distinct from participatory research, where "members of the organization studied become active participants in the research process-but where that process itself is not linked directly to action" (Whyte 1989, p. 506). PAR, in contrast, builds action objectives into the research design from the outset (Park 1999).

\section{CASE STUDY: IMPLEMENTING COMMUNITIES OF PRACTICE}

This section recounts the PAR stage of a longitudinal study of communities of practice (COPs), carried out in two phases over a period of 32 months (see Figure 1). The researchers became involved with the organization through a consortium-funded project, comprising case studies ofCOPs in five large organizations (phase 1). Phase 2 continued the project with one sponsor, ServiceCo (a pseudonym), a public services organization, The aim of the engagement was to foster COPs as a strategy for improving knowledge sharing among its 2,500 staff who mostly work at client sites.

The project sponsor (ProSpo) worked at head office and reported directly to the board member responsible for knowledge management (KMDir). ProSpo invited five peers onto the research team. The academic researchers reported to ProSpo and the COP Steering Group. The research team agreed on PAR as the method for collaboration 


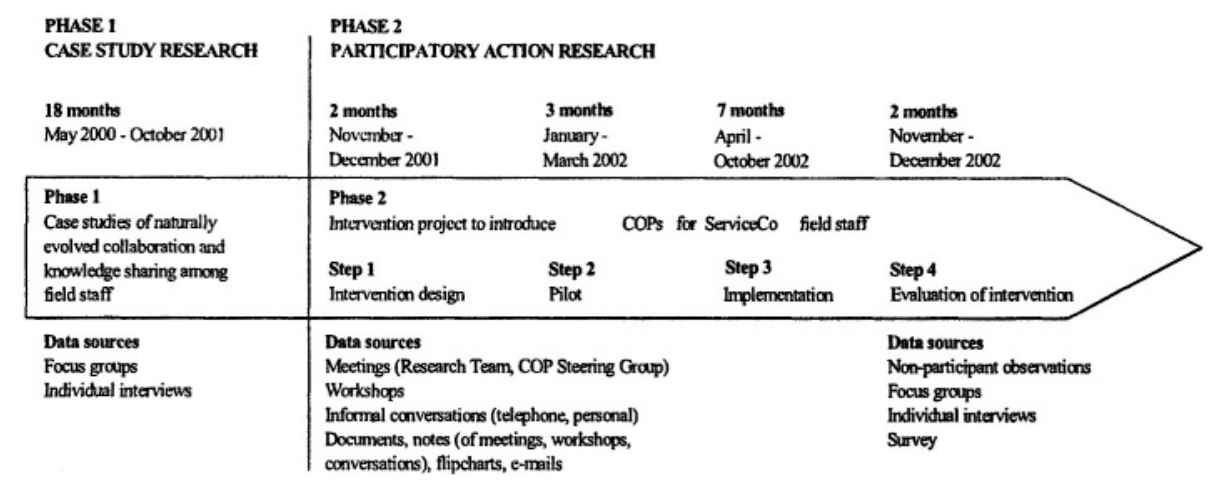

Figure 1. Research Process in ServiceCo

and jointly developed the intervention plan. To ensure that the practitioners understood the plan, the researchers coauthored the intervention plan with ProSpo and obtained its approval by KMDir.

The research team tested and subsequently revised the implementation plan through a pilot with three trial COPs and proceeded to implementation with another six COPs. Aiming to create COPs as espoused in the literature, which recommends fostering but not interfering with community development, the research team withdrew from the field after facilitating one-day start-up workshops with each COP. Given that COPs would meet bimonthly, we returned to the field after seven months, allowing each COP to meet three times. The researchers then evaluated the impact of the intervention through nonparticipant observations, focus groups, individual interviews, and a structured survey. The results revealed fundamental digressions from the intervention plan.

\section{REFLECTIONS ON THE ROLE OF POWER IN THE PAR TEAM}

PAR defines new roles for the actors in the research process. Researchers on PAR teams are empowered to act as change-effecting practitioners and practitioners as knowledge creators. Both parties must exchange some professional powers, an arrangement that potentially intensifies the team's power dynamics.

Power theories regard power either as an object that people possess, lose, share, fight for and win, or as force relations that people exercise in strategies and tactics. The power as an object view is concerned with sources and outcomes of power (Lukes 1986), whereas the power as force relations view draws attention to the exercise of power (Foucault 1979).

\subsection{Sources of Power}

The most evident sources of power in our PAR engagement concerned knowledge and credibility, on the part of the researchers, and provision of funding and access to the field on the part of the practitioners (see Figure 2). 


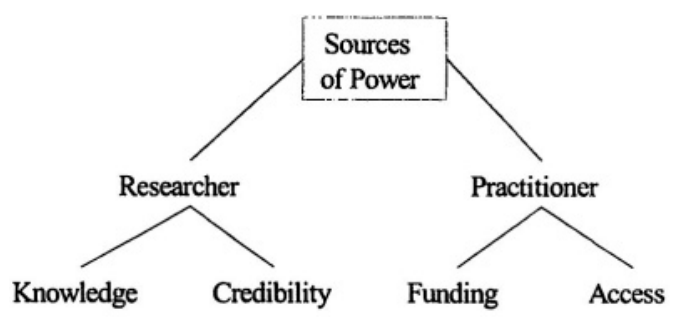

Figure 2. Sources of Power on the PAR Team

The practitioners explained that they preferred academic partners to commercial researchers and consultants. Given our commitment to theoretical and methodological rigor, they perceived our academic knowledge as generally superior and particularly relevant to the problems they were seeking to address. Our involvement in the engagement, furthermore, was seen as an endorsement of the intervention by an impartial and credible third party. We, in contrast, have obligations to raise funding for our research activities and gain access to organizations to carry out empirical research. The desire to obtain each others' resources creates dependencies in the research engagement that furnished those who hold the resources with an opportunity for exercising power.

\subsection{Uses of Power}

ProSpo contributed to the demise of the academic goals of the project by using his power to control access to the COPs as a means for digressing from the agreed intervention plan in several respects. (1) Rather than publicizing the COP initiative organization-wide, ProSpo discarded the jointly developed communications plan and invited COP participation selectively. (2) Rather than allowing COPs to select their leaders themselves, ProSpo recruited COP leaders from his personal network. (3) Rather than creating COPs for field staff, ProSpo allowed four out of nine COPs to convene senior decision makers who then exercised a closed access policy for peers of equal seniority. (4) Although requesting a list of the entire COP population, by the end of the evaluation it became apparent that ProSpo had provided us with a contrived sample. In this way, he silenced critical voices and neutralized negative evidence, creating a positive impression of the intervention outcomes for ServiceCo's decision makers and budget holders. Once the practical interests of the research were satisfied, ProSpo ended the engagement, although the theoretical aims of the inquiry had not yet been fulfilled. The consequence for us was that the requirements of publishable research, particularly data quality, theoretical saturation, and methodological rigor, were not met.

The condition of funding constituted a major dependency for us. The relationship was defined, from a financial point of view, as an exchange of money for research results because we used a contract format that is typical for commissioned research. It specifies no obligation for practitioners to coproduce knowledge and honor the agreed research methodology. As a result, ProSpo could insist on obtaining the research results that he had specified, whereas we had no power to enforce his compliance with the agreed methodology in the absence of such contractual obligations. 
We, as the academics, share responsibility for the decline of PAR. First, we were too trusting of ProSpo to follow the plans as agreed. We assumed that our trust was well placed, as we had a history of successful work with ProSpo albeit using a different research strategy (phase 1), and also because the jointly developed intervention plan was signed-off by KMDir. Second, we were unaware of the implications of the chosen contractual terms for our ability to influence events. Once we had seen the full extent of ProSpo's deviation from the agreed plans, we had no basis for withdrawing from the engagement.

\section{CONCLUSION}

The application of PAR in industry-funded IS research, our experience would suggest, challenges fundamental paradigmatic assumptions, both explicit and implicit, of the participatory ideology. An explicit assumption of PAR is that knowledge is power and the ability to create knowledge is power (Freire 1970; Reason 1993). We experienced that knowledge was a weak source of power for us, as ProSpo's senior managerial authority allowed him to override intervention plans cocreated by the research team and alter previously agreed courses of action.

PAR implicitly assumes that credibility of the researchers does not influence the power dynamic within a research team and makes no mention of money as a potential source of power. In our case, credibility proved to be a weak source of power for us. Credibility helped us win the contract, and was used by ProSpo to create favorable perceptions with the stakeholders affected by the implementation, but did not help us in redressing the balance on the PAR team and rectifying the course of the implementation.

Lack of financial independence of academic institutions is a general condition that weakens academic researchers' power base. The dependency of academic institutions on funding from external sources brought about the use of contracts for research that typically reflects a transactional model of research, whereby money is exchanged for research results solely produced by the researchers. This, however, is inappropriate for participatory research, which requires the full contribution of the practitioners to the inquiry process in their capacity as coresearchers.

To address the challenges of using PAR in industry-funded research, we make the following suggestions. From a collaboration point of view, research teams should negotiate a broader collaboration base within the sponsoring organization. This would limit opportunities for individual practitioners unduly influencing the course of the engagement. From a contractual point of view, we suggest to devise contracts that reflect the principles of PAR by specifying the duty for the practitioners to fulfil the principles of authentic collaboration by researching, designing, and actioning all aspects of an intervention jointly (Reason 1999). While we recognize that contractual terms cannot engender genuine collaboration, they, at least, legitimize and thereby empower the researcher to withdraw from a failing PAR engagement.

Although we made suggestions for addressing the challenges of PAR, we do not believe that the PAR ideology can be followed truthfully to its principles in industryfunded IS research. The practitioner members on a research team possess authority in their organizations which exceeds, in our view, the power that academics can draw from 
their knowledge. This condition inevitably creates a power imbalance in a PAR team that undermines the democratic ideal of PAR, and we do not see how that can be overcome.

\section{REFERENCES}

Fals-Borda, O., and Rahman, M. A. Action and Knowledge: Breaking the Monopoly with Participatory Action-Research, New Delhi: Indian Social Institute, 1991.

Freire, P. Pedagogy of the Oppressed, New York: Herder and Herder, 1970.

Foucault, M. Discipline and Punish, New York: Vintage Books, 1979.

Heron, J. "Philosophical Basis for a New Paradigm," in P. Reason and J. Rowan (Eds.), Human Inquiry: A Sourcebook ofNew Paradigm Research, Chichester, England: John Wiley, 1981, pp. 19-35.

Heron, J., and Reason, P. “A Participatory Inquiry Paradigm,” Qualitative Inquiry (3:3), 1997, pp. 274-294.

Lukes, S. Power, Oxford: Basil Blackwell, 1986.

Park, P. "People, Knowledge, and Change in Participatory Research," Management Learning (30:2), 1999, pp. 141-157.

Reason, P. "Integrating Action and Reflection through Co-operative Inquiry," Management Learning (30:2), 1999, pp. 207-226.

Reason, P. "Sacred Experience and Sacred Science," Journal of Management Inquiry (2:3), 1993, pp. 10-27.

Skolimowski, H. The Participatory Mind: A New Theory ofKnowledge and of the Universe, London: Arkana Books, 1994.

Whyte, W. F. "Introduction," American Behavioral Scientist, Special Issue: Action Research for the Twenty-First Century: Participation, Reflection, andPractice (32:5), 1989, pp. 502512.

\section{ABOUT THE AUTHORS}

Karin Breu is a senior research fellow in Information Systems at Cranfield School of Management. Her research focuses on the application of information technology to the workplace, including empirical studies of collaborative, virtual, and mobile working. Karin can be reached at k.breu@cranfield.ac.uk.

Christopher J. Hemingway is a research fellow in Information Systems at Cranfield School of Management. His research focuses on performance and management information, including studies of analytics and business intelligence. Chris can be reached at c.j.hemingway@ cranfield.ac.uk.

Joe Peppard is a professor of Information Systems at The Business School, Loughborough University where he researches and teaches in the area of information systems and technology, strategy and management. Joe can be reached at joe.peppard@lboro.ac.uk. 